\title{
RHETORIK-FORSCHUNGEN
}

\author{
Herausgegeben von \\ Joachim Dyck, Walter Jens und Gert Ueding
}

Band 10 

Elizabeth Ann Gondos

\section{Auf dem Weg zur rhetorischen Theorie}

Rhetorische Reflexion im ausgehenden fünften Jahrhundert v. Chr.

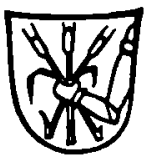

Max Niemeyer Verlag

Tübingen 1996 


\section{Für Uli}

Die Deutsche Bibliothek - CIP-Einheitsaufnahme

Gondos, Elizabeth Ann:

Auf dem Weg zur rhetorischen Theorie : rhetorische Reflexion im ausgehenden fünften Jahrhundert v. Chr. / Elizabeth Ann Gondos. - Tübingen : Niemeyer, 1996

(Rhetorik-Forschungen ; Bd. 10)

Zugl.: Tübingen, Univ., Diss., 1995

NE: GT

ISBN 3-484-68010-5 ISSN 0939-6462

(c) Max Niemeyer Verlag GmbH \& Co. KG,Tübingen 1996

Das Werk einschließlich aller seiner Teile ist urheberrechtlich geschützt. Jede Verwertung außerhalb der engen Grenzen des Urheberrechtsgesetzes ist ohne Zustimmung des Verlages unzulässig und strafbar. Das gilt insbesondere für Vervielfältigungen, Übersetzungen, Mikroverfilmungen und die Einspeicherung und Verarbeitung in elektronischen Systemen. Printed in Germany.

Gedruckt auf alterungsbeständigem Papier.

Druck: Weihert-Druck GmbH, Darmstadt

Einband: Heinr. Koch, Tübingen 